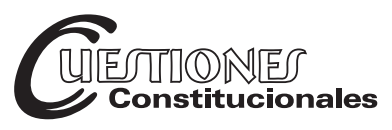

Revista Mexicana de Derecho Constitucional Núm. 39, julio-diciembre 2018

\title{
Del control de constitucionalidad en Cuba. Propuestas necesarias
}

\author{
The Control of Constitutionality in Cuba. \\ Necessary Proposals
}

\section{Martha PRIETo VAldÉS*}

RESUMEN: El control de la constitucionalidad de las leyes y demás disposiciones generales siempre es un tema de interés por esa mezcla de política, derecho, seguridad jurídica y justicia que el mismo implica; como medio de asegurar al poder, de ponerle límites y de brindar la vía para la instrumentación constitucional de los postulados superiores y sus contenidos. Pero también es cierto que no hay un modelo único y la mirada a Cuba permite mostrar una diversidad de fórmulas posibles, de avances y retrocesos, de las que se bebe para sustentar estas propuestas para la instrumentación efectiva del control político actual, aún por despertar. También se hacen otras sugerencias pensando la reforma constitucional, que habrá de adoptar modelos dinámicos en pos de salvaguardar efectivamente la supremacía constitucional y la justicia en una sociedad que se ha asentado en los valores de "bienestar individual y colectivo".

Palabras clave: control político, control judicial, control de constitucionalidad.
ABSTRACT: The control of the constitutionality of the laws and other general dispositions are always a topic of interest for the mixture of Politic, Law, Security and Justice that it implies, assuring to the Power, putting him limits and offering the road for the constitutional instrumentation of the superior postulates and their contents. However, it is also certain that there are not a unique model, and looking to Cuba show the diversity of theses possible formulas, of advances and setbacks, of those may sustain these proposals for instrumenting the current political control, still to wake up. Other suggestions are also make thinking about the next constitutional reform that will adopt dynamic model to safeguard the constitutional supremacy and the justice in a society that has settled on the values of individual and collective "well-being".

Keywords: Political Control; Judicial Control; Control of the Constitutionality.

* Profesora titular de Teoría general del derecho y Derecho constitucional, Universidad de La Habana.mprieto@lex.uh.cuba. 
Esta revista forma parte del acervo de la Biblioteca Jurídica Virtual del Instituto de Investigaciones Jurídicas de la UNAM

Sumario: I. Cuestiones metodológicas previas. II. Antecedentes mínimos. III. El hoy, ¿efectividad? IV. Lo necesario en el hoy y el futuro inmediato para asegurar legitimidad y justicia. V. In fine.

\section{Cuestiones Metodológicas PREVIAS}

El presente artículo es resultado de un amplísimo estudio personal, ${ }^{1}$ iniciado en los años noventa, sobre el tema del control de la constitucionalidad de las leyes y la diversidad de mecanismos posibles para asegurar la supremacía del magno texto y de sus contenidos, exigencia mínima garante en la esfera jurídica de derechos, igualdad, seguridad, justicia, sin desconocer

1 Artículos de la autora de este trabajo que abordan el control, ya directa o indirectamente: "Garantías y defensa de los derechos fundamentales de la ciudadanía cubana", El Otro Derecho, Colombia, vol. 6, núm. 2, 1994; "Reflexiones en torno al carácter normativo de la Constitución", "La defensa de la Constitución y la reforma constitucional de 1992", en Pérez y Prieto, Temas de derecho constitucional cubano, La Habana, F. Varela, 2000, pp.12-17 y 214-217; "La defensa jurídica de la Constitución cubana", Cuba, Siglo XXI, 2002, disponible en: www.nodo50.org; "Sistema de defensa constitucional en Cuba", Revista Hispanoamericana de Derecho, Universidad de Huánuco, Perú, 2004, año 1, núm. 2; Revista Cubana de Derecho, 2006, pp. 25-53; Matilla Correa, A. (comp.), Estudios cubanos sobre control de constitucionalidad (1901-2008), México, Instituto Mexicano de Derecho Procesal Constitucional-Porrúa, 2009, pp. 455-485; "Criterios doctrinales predominantes acerca del derecho en Cuba y su aplicación en el periodo posterior a 1959", en Berizonce, Roberto y Mendoza, Juan (coords.), Tendencias actuales del derecho: Cuba-Argentina, La Plata, 2006, pp. 41-60; “El derecho, la Constitución y la interpretación", en Pérez Gallardo, Leonardo (coord.), Perspectiva del derecho cubano actual, Madrid, Reus, 2006, pp. 31-97; "En pos de la aplicabilidad directa de la constitución cubana de 1976 (un breve comentario)", Revista IUS, ICI-Instituto de Ciencias Jurídicas de Puebla, nueva época, año II, primavera de 2008, pp. 193-204; Revista Cubana de Derecho, núm. 31, enero-julio de 2008, La Habana, UNJC, pp. 5-18; Universia, Biblioteca.net, 2010-11, disponible en: http://biblioteca.universia.net/index.htm; "La Constitución, los derechos y el control. De Cuba, propuestas" (con Amanda L. Prieto Valdés), en Huck, W. y Pérez, Y. (eds.), Derecho, economía y sociedad en el siglo XXI (Recht, Wirtschaft und Gesellschaft im 21.Hahrhundert), Hamburgo, Band I, Velag Dr. Kovač, 2013, pp. 137-153, disponible en www.verlagdrkovac.de/3-8300-7339-9.htm; "El control de constitucionalidad en Cuba. ¿Qué aprovechar del pasado para instrumentar en el presente?", CUBALEX, núm. 33, año 16, tercera época, enero-diciembre de 2013, disponible en: http://vlex.com/source/revista-cubalex-12125; "Las garantías constitucionales de los derechos fundamentales y la Constitución de 1976", en Matilla Correa, Andry (coord.), La Constitución cubana de 1976, 40 años de vigencia, La Habana, UH-UNIJURIS, 2016, pp. 170-188. 
su importancia para la salvaguarda de los diseños socioeconómicos y políticos definidos en los textos.

Por tal motivo, en este trabajo sólo se aportan algunos análisis del tema, con la mirada permanente en Cuba, que aún preserva un control de tipo político, pero tiene experiencia en la intervención del aparato de justicia en la materia, y con eficacia, a pesar de una añeja decisión circunstanciada y absurda desde la óptica democrática. Se vuelve sobre el tema en función de la actual reforma de la administración y del Estado, como consecuencia de transformaciones económicas con alto impacto en las esferas social, cultural, ideológico-política y, como es de suponer, en la jurídica, exigiendo reformas de la Constitución. Por consiguiente, la finalidad es volver a llamar la atención sobre lo imperioso de hacer efectivo el control de constitucionalidad, con la intervención de múltiples actores.

\section{ANTECEDENTES MÍNIMOS}

¿Por qué unos antecedentes mínimos, si el objeto es el hoy y cómo perfeccionar o hacia dónde modificar el actual diseño de control de constitucionalidad en Cuba? No es nostalgia o miradas acríticas, sino recordar cómo se fue formando el valioso modelo mixto de control judicial de la constitucionalidad en Cuba que impactó en nuestra América latina, y del que es necesario beber hoy de manera inmediata en pos de la coherencia del ordenamiento jurídico y político y de la eficacia de los postulados constitucionales.

Aunque hay ejemplo de control de constitucionalidad en una propuesta de Constitución, ${ }^{2}$ cuando éramos parte del territorio colonial español, el primer diseño republicano, instituido, para revisar las cuestiones constitucionales en Cuba, estuvo asentado, al amparo de la Constitución que entró en vigor en 1902. Concentrado en el Tribunal Supremo de Justicia, la Ley orgánica de 1903, fijó la manera de acceder al magno órgano mediante un "recurso de carácter especial", "remedio extraordinario, vía especial", 3 ya fuere por vía de casación para actuaciones judiciales o la directa para los

2 Véase Infante, Joaquín, Proyecto de Constitución para la Isla de Cuba, 1810, artículo 1o., título II, del Poder Legislativo, 6. Al Consejo pertenece... el examen, conservación o anulación de todo acto inconstitucional.

3 Véase Merino, Eloy, El recurso de inconstitucionalidad y su jurisprudencia, La Habana, Cultural, 1938, p. 15, sobre precisiones realizadas en el momento de la pre- 
restantes casos, bajo la forma de "recurso de inconstitucionalidad por vía de casación", y siempre que fuere objeto de controversia entre las partes. ${ }^{4}$ Muy importante, marcando otra diferencia con el modelo americano y algunos latinoamericanos existentes, el pleno del Tribunal podía declarar nulas las disposiciones que se dictaren para regular el ejercicio de derechos si en cualquier forma los disminuían, restringían o adulteraban.

Las exigencias sociales de la época y la necesidad de salvar algunas incongruencias, condicionaron una nueva Ley Orgánica en 1922, que ensanchó extraordinariamente el ámbito del fuero constitucional, ${ }^{5}$ ya que la reiteración de sentencia de inconstitucionalidad mandataba a la entidad a modificar o derogar la disposición, y de no hacerlo ésta perdía obligatoriedad; ${ }^{6}$ un requerimiento excelente si se quiere obligar a reconocer la fuerza de la decisión judicial, pero que lastraba la separación de funciones sobre la que se articuló el Estado. La práctica ulterior definió que la reiteración de sentencia dejaba sin efecto la normativa.

Otra innovadora fórmula apareció un poco más tarde, en 1934, cuando se ampliaron los sujetos que podían estimular el análisis por el Tribunal Supremo de Justicia; ahora no era sólo a la parte afectada, sino también a favor de 25 ciudadanos que se encontrasen en pleno goce y ejercicio de sus derechos civiles y políticos; ${ }^{7}$ acción pública colectiva que permitía, ade-

votación durante la constituyente de 1901, lo cual introdujo una modificación respecto a la práctica judicial de los Estados Unidos.

4 Constitución de 1901, artículo 83, además de las atribuciones que le estuvieren formalmente señaladas... corresponden al Tribunal Supremo... apartado 4o. Decidir sobre la constitucionalidad de las leyes, decretos y reglamentos, cuando fuere objeto de controversia entre partes.

5 Maza, Emilio, "El recurso de inconstitucionalidad: sus fuentes actuales", Revista Cubana de Derecho, La Habana, año XVIII (4 nueva serie), núm. II (70), abril-junio de 1944, Imprenta de F. Verdugo, p. 143.

6 La Ley de 17 de marzo de 1922, establecía en su artículo 4o. que: Siempre que el Tribunal Supremo declare inconstitucional en más de dos sentencias un decreto, reglamento, resolución, o disposición de carácter, general, la autoridad que lo hubiese dictado procederá, dentro del término de veinte días siguientes al de la publicación de la sentencia en la Gaceta Oficial, a derogar o modificar la disposición salvando la infracción de la Constitución que en el anterior hubiere incurrido. Si transcurriere el expresado término sin realizar lo uno ni lo otro, la disposición impugnada perderá toda su eficacia y dejará de ser obligatoria en cuanto haya sido declarada contraria a la Constitución.

7 Véase Ley Constitucional de 1934, artículo 78. ...corresponden al Tribunal Supremo... apartado 5o. Decidir sobre la constitucionalidad de las leyes, decretos-leyes, acuerdos, decretos, reglamentos, órdenes, disposiciones o actos de cualquier clase, 
más de reclamar de conjunto a los interesados, evidenciar que la contradicción rebasaba lo particular. Una magnifica vía de intervención ciudadana en el control indirecto, resultado de una interesante formulación constitucional que autorizaba a cualquier ciudadano ${ }^{8}$ a solicitar la declaración de inconstitucionalidad cuando las normativas restringieren los derechos. No obstante, fue discutida ${ }^{9}$ al entenderse que la regulación tenía incongruencias ante la ausencia de previsión expresa para tal acción existiendo otras vías que estimulasen el recurso de inconstitucionalidad. ${ }^{10}$

Un año más tarde, y en una lógica más garantista de la coherencia normativa, a través de la Ley Constitucional de 1935, se previó la posibilidad, ya directa, de que el Tribunal Supremo, su Pleno, declarare la nulidad de leyes y disposiciones de cualquier clase que provocaren disminución, restricción o adulteración del ejercicio de los derechos constitucionales, sin fijar límite de tiempo cuando en defensa de los derechos se establecía recurso por 25 ciudadanos afectados.

En esa línea de transformaciones hacia un modelo de jurisdicción especial, un cambio, desde el punto de vista orgánico, se expresó a través de la Ley de Reforma Constitucional de 1936, ${ }^{11}$ mediante la creación de una

sean cuales fueren el poder, autoridad o funcionario que los hubieren dictado o de que emanaren, a petición de parte afectada o a solicitud suscrita por no menos de veinticinco ciudadanos que estén en el pleno goce y ejercicio de sus derechos civiles y políticos cuando fuere objeto de controversia entre partes...

8 Ibidem, artículo 38. Las leyes, decretos, decretos-leyes, reglamentos, órdenes y disposiciones de cualquier clase, sean cuales fueren el poder, autoridad o funcionario que los hubieren dictado, que regulen el ejercicio de los derechos que esta Ley Constitucional garantiza, serán nulos si los disminuyen, restringen o adulteran.

El Tribunal Supremo lo declarará así a petición, en todo tiempo, de cualquier ciudadano en la forma que determina esta Ley Constitucional para los recursos de inconstitucionalidad, sin que puedan volver a aplicarse.

9 Sobre los criterios y cuestionamientos al diseño, así como respecto a los defectos formales que podían limitar el curso del proceso, véase Montagú, Guillermo de, "Defectos formales del recurso de inconstitucionalidad", El Poder Judicial y la Constitución y otros estudios, La Habana, Cultural, 1952, pp. 27-40.

10 Véase Montagú, Guillermo de, "El recurso de inconstitucionalidad de un solo ciudadano", en Matilla Correa, A. (comp.), Estudios cubanos sobre control de constitucionalidad (1901-2008), cit., pp.13-26.

11 Ley de Reforma Constitucional de 1936, artículos 119-2 y 4), 121-123. Por ejemplo, artículo 121. El Tribunal de Garantías Constitucionales, cuya jurisdicción se extiende a todo el territorio de la República, es competente para conocer...1) los recursos de inconstitucionalidad contra Leyes... que disminuyan, restrinjan o adulteren los derechos de seguridad personal, el sufragio y los preceptos constitucionales sobre suspensión de 
Sala especial en el Tribunal Supremo. Se caminaba aquí hacia un modelo propio, concentrado, que permitía reclamar derechos y efectuar el control con efectos generales, y que sentó las bases sobre las que se erigió la Constitución de 1940. Y fue así que, este último texto, vino a sentar las bases de un modelo de justicia constitucional que sirvió de pauta para los diseños adoptados con posterioridad en América Latina, el que se perfeccionó a partir de la Ley del Tribunal de Garantías Constitucionales y Sociales en 1949. Fue esta ley especial la que acabó con la supervivencia de la Ley Constitucional de 1935, que en materia de constitucionalidad aún pautaba, y en la que quedaron claramente definidas las competencias de este nuevo ente, ${ }^{12}$ cuyas decisiones se determinaron como inapelables.

Este diseño que se comenta, aun cuando se configuró el control a manos de una Sala Especial del Tribunal Supremo, el hecho de denominarse Tribunal de Garantías Constitucionales y Sociales, supuso una cierta independencia y superioridad sobre las salas del órgano supremo, aunque se insertaba en una unidad sistémica del aparato de justicia. Se configuró como un órgano con carácter propio, sin exageraciones ni restricciones, como Tribunal que actuara de acuerdo con procedimientos judiciales, a instancias de las personas titulares de las acciones y según las materias de su competencia. ${ }^{13}$ Entonces, se previeron importantes facultades, como conocer de los recursos de inconstitucionalidad contra las leyes, decretosleyes, decretos, resoluciones o actos en defensa de los derechos y garantías constitucionales o funcionamiento de los órganos del Estado, los análisis de validez de procedimientos y reformas constitucionales, el recurso contra abuso de poder y otras cuestiones de carácter jurídico político y social que la Constitución o las leyes sometiesen a su consideración. ${ }^{14}$ Se reiteró

garantías, o impidan el libre funcionamiento de los órganos del Estado; 2) los recursos de habeas corpus cuando haya sido ineficaz la reclamación ante otras autoridades o tribunales; 3) la legitimidad de alguna reforma constitucional; 4) la responsabilidad criminal del presidente de la República..., y 5) las cuestiones jurídico políticas de las leyes... Igualmente, vale consultar a Merino, Eloy, El recurso de..., cit., pp. 49 y ss.

12 Ley núm. 7, de 31 de mayo de 1940, artículos 2o. y 7o., respecto a la integración y la presidencia asignada al presidente del Tribunal Supremo en temas de constitucionalidad.

13 Albanes, Wilfredo, "Prólogo", en Lazcano y Mazón, A., Comentarios a la Ley del Tribunal de Garantías Constitucionales y Sociales, La Habana, Librería Selecta, 1949, p. 9.

14 Véase Constitución de 1940, artículo 174, inc. d), para la facultad del Tribunal Supremo de Justicia de decidir sobre la constitucionalidad de las leyes y demás disposiciones generales y artículo 182 para las competencias particulares del Tribunal de 
la posibilidad de solicitar la declaración de inconstitucionalidad por 25 ciudadanos, además la de persona afectada directamente por disposición general, o por interesados en juicios ordinarios, con efectos ex nunc para lo general, y en caso de parte afectada también reconoció los efectos ex tunc, además de restablecer el derecho lesionado. ${ }^{15}$

Tampoco es posible desconocer este diseño desde una perspectiva actual, la consideración de inaplicable de aquel precepto ordinario que violase la Constitución, y ante el cual los jueces inferiores debían suspender el procedimiento y elevar el asunto al Tribunal de Garantías para que fuere éste el que declarase la constitucionalidad o no del precepto en cuestión, y lo remitiera al tribunal actuante para que resolviera de conformidad con la decisión anterior. ${ }^{16}$ Una manera efectiva de intervenir el aparato ordinario,

garantías constitucionales y sociales: el Tribunal de Garantías Constitucionales y Sociales es competente para conocer los siguientes asuntos: a) los recursos de inconstitucionalidad contra las leyes, decretos-leyes, decretos, resoluciones o actos que nieguen, disminuyan, restrinjan o adulteren los derechos y garantías consignados en esta Constitución o que impidan el libre funcionamiento de los órganos del Estado; b) las consultas de jueces y tribunales sobre la constitucionalidad de las leyes, decretos-leyes y demás disposiciones que hayan de aplicar en juicio; c) los recursos de habeas corpus, por vía de apelación, o cuando haya sido ineficaz la reclamación ante otras autoridades o tribunales; d) la validez del procedimiento y de la reforma constitucional; e) las cuestiones jurídico-políticas y las de legislación social que esta Constitución y la Ley sometan a su consideración, y f) los recursos contra los abusos de poder.

15 Garcerán de Vall, José, El proceso de inconstitucionalidad, La Habana, Librería Martí, 1947, p. 437.

16 Véase Constitución de 1940, artículo 194: "La declaración de inconstitucionalidad podrá pedirse: a) por los interesados en los juicios, causas o negocios de que conozcan la jurisdicción ordinaria y las especiales, b) por veinticinco ciudadanos que justifiquen su condición de tales, c) por la persona a quien afecte la disposición que estime inconstitucional. Los jueces y tribunales están obligados a resolver los conflictos entre las leyes vigentes y la Constitución, ajustándose al principio de que ésta prevalezca siempre sobre aquélla.

"Cuando un juez o tribunal considere inaplicable cualquier ley, decreto-ley, decreto o disposición porque estime que viola la Constitución, suspenderá el procedimiento y elevará el asunto al Tribunal de Garantías Constitucionales y Sociales a fin de que declare o niegue la constitucionalidad del precepto en cuestión y devuelva el asunto al remitente para que continúe el procedimiento, dictando las medidas de seguridad que sean pertinentes.

“...En todo recurso de inconstitucionalidad los tribunales resolverán siempre el fondo de la reclamación. Si el recurso adoleciere de algún defecto de forma, concederá un plazo al recurrente para que lo subsane. 
sin tomar decisiones que podrían haberse considerado injerencistas por parte del Legislativo o el Ejecutivo.

Llegado a este punto, si seguimos admitiendo que aun cuando la interpretación constitucional es circunstanciada, la finalidad de tal acción es la de su defensa, ${ }^{17}$ ¿por qué no aprovechar entonces esta formulación, ante las normativas restrictivas de derechos, del acceso a la justicia, o que desatienden la letra constitucional, para solucionar antinomias, desregulaciones y vacíos ocasionales en el presente? Por eso, es prudente separar, y dejar en el pasado la triste, deplorable y absurda decisión de aquel Tribunal, validando la ley constitucional aprobada por los golpistas de 1952, la que usurpó el lugar de la Constitución de $1940,{ }^{18}$ aun en contra de los recursos presentados y el clamor popular. Ello marcó profundamente la apreciación de la legitimidad material y jurídica de este órgano y su posibilidad de ser garante de la supremacía constitucional, así como de los derechos del pueblo.

No es de extrañar entonces, que a partir de tal hecho una mirada crítica se volcara sobre aquel Tribunal de Garantías Constitucionales y Sociales; y aquella "independencia" funcional se hiciera ceder con el paso de los años, aun cuando se preservó en la ley fundamental de 1959, adoptada por el Gobierno Provisional Revolucionario luego del triunfo. Se conservó la Sala de Garantías Constitucionales y Sociales, y formalmente la Ley mantuvo la denominación de Tribunal. Igual que al amparo de las normativas

"No podrá aplicarse en ningún caso ni forma, una ley, decreto-ley, decreto, reglamento, orden, disposición o medida que haya sido declarada inconstitucional, bajo pena de inhabilitación para el desempeño de cargo público.

"La sentencia en que se declare la inconstitucionalidad de un precepto legal o de una medida o acuerdo gubernativo, obligará al organismo, autoridad o funcionario que haya dictado la disposición anulada, a derogarla inmediatamente.

"En todo caso la disposición legislativa o reglamentaria o medida gubernativa declarada inconstitucional, se considerará nula y sin valor ni efecto desde el día de la publicación de la sentencia en los estrados del Tribunal”.

17 Véase Merino Brito, Eloy, La interpretación constitucional, pról. de E. Menéndez, La Habana, Jesús Montero Editor, 1949, p. 30.

18 Portuondo y de Castro, José, En Defensa de la Constitución, La Habana, Cuba Intelectual, 1957. En esta obra se consigna el escrito de adhesión de Portuondo ante el Tribunal de Garantías Constitucionales y Sociales, apoyando al Recurso de Inconstitucionalidad presentado por Cosme de la Torriente y Peraza, Ramón Zaydin y Márquez Sterling y otros, contra los Estatutos Provisionales adoptados por los golpistas y que sustituían a la Constitución de 1940. 
anteriores, estaba presidida por el presidente del Tribunal Supremo para las cuestiones de constitucionalidad. ${ }^{19}$

En este periodo también fueron objeto de modificaciones los procedimientos referidos a las materias de tierras e inmuebles urbanos al amparo de las leyes de Reforma Agraria y de Reforma Urbana. La primera de las anteriores proscribió el latifundio y estipuló la expropiación forzosa; en tanto la segunda suprimió el arrendamiento de viviendas y permitió que éstas pasaran a la titularidad de los ocupantes. Decisiones que introdujeron transformaciones en la esfera social, y aun cuando afectaron la propiedad privada tutelada constitucionalmente, las reclamaciones de los propietarios afectados se sustanciarían solamente en la vía judicial ordinaria o frente a entes administrativos. El hecho de declararse en las propias leyes que se comentan que eran parte de la Ley Fundamental, desbarataba los argumentos de inconstitucionalidad que pudieran presentarse..$^{20}$ Incluso, en esos cambios pervivían algunas ideas en defensa del recurso de inconstitucionalidad ${ }^{21}$ como garantía para afirmar la intangibilidad de la Constitución en cuanto normativa dentro de la cual se desarrolla cada pueblo.

Mirando al presente, ¿no es tiempo ya de tener claro que los órganos son más o menos funcionales, actúan con mayor o menor lógica, como consecuencia de sus integrantes, y no de la esencia del ente? Por ello mismo, a pesar del rechazo previo, vale destacar la magnífica función que desempeñó esta Sala de Garantías en los primeros años con posterioridad al triunfo revolucionario, y que permitió adecuar el viejo derecho a los nuevos tiempos, defendió el que se iba creando en coherencia con las nuevas

19 Ley Fundamental, de 7 de febrero de 1959. Véase artículos 150 y 160 respecto a la existencia del órgano y su competencia.

20 Véase las disposiciones finales de las Leyes de Reforma Agraria, de 3 de junio de 1959, y de Reforma Urbana, de 14 de octubre de 1960, que les aseguraron fuerza y jerarquía constitucionales.

21 Muestra de la afirmación anterior puede tenerse con la magnífica obra de Fernando Álvarez Tabío (magistrado del Tribunal Supremo) sobre el tema. Véase Recurso de Inconstitucionalidad, La Habana, Librería Martí, 1960. 
condiciones y las amparaba, ${ }^{22} \mathrm{o}$ impedía la aplicación de reglas vigentes no congruentes con la nueva realidad. ${ }^{23}$

No obstante ese valioso desempeño, la actividad de la Sala fue cediendo paulatinamente frente a las transformaciones profundas en el diseño político-social y económico, e incluso ante a la nueva organización del poder que centralizaba la toma de decisiones, lo que se constata en la clara decisión de la Sala de no propiciar — en la esfera judicial— el desarrollo de cuestionamiento político en aquellos momentos de la construcción social del nuevo sistema. ${ }^{24}$

En consecuencia de lo anterior, ya para los primeros años de la década del 70 tenía muy poca actividad, y fue la reforma del sistema judicial en

22 Véase Sentencia de la Sala de Garantías Constitucionales y Sociales, núm. 7, 3 de junio de 1969: “...cuando surge un nuevo derecho que va a inaugurar una institución, el fundamento de su legitimidad no dimana del orden jurídico anterior puesto que no la sustentan; el nuevo instituto... tiene una base de validez diferente... valen y rigen porque el poder revolucionario las ha aceptado como propias...", cfr. Prieto Valdés, Martha, "La Constitución. Generalidades", en Prieto Valdés (coord.), Curso de preparación jurídica para cuadros del Estado, La Habana, Félix Varela, 2001, p. 75.

23 Véase Sentencia de la Sala de lo Penal, núm. 162, 18 abril de 1969 (Boletín, Tribunal Supremo, núm. 2, año IV, marzo-abril de 1969, pp. 163 y 164), en la que estableció: “... en este país en los tiempos que corren, nadie puede alegar en su beneficio la falta de ingresos económicos para subsistir... porque la sociedad revolucionaria tiene medios y los usa adecuadamente para que el ciudadano no sufra privaciones que lo obliguen a sustraer cosas ajenas...”. De la fundamentación anterior, haciendo un análisis más profundo permite reconocer en ella una declaración de inaplicabilidad y de obsolescencia de un precepto del Código Penal, aun cuando no había sido éste derogado expresamente. Cfr. Prieto Valdés, Martha, "La Constitución. Generalidades", cit., nota anterior.

24 Durante el periodo 1959-1976, la Sala de Garantías Constitucionales y Sociales refiriéndose al texto de 1959, reconoció sólo carácter programático de los postulados constitucionales, Sentencia núm. 2, 5 de mayo de 1967, Boletín de mayo de 1967, p. 3; o que la ausencia de la norma de desarrollo del precepto constitucional impide la entrada en vigor del mismo, Sentencias núm. 5, 8 de junio de 1966, Boletín de junio de 1966, pp. 8 y 9, núm. 9, 29 de julio del propio año, Boletín de julio de 1966, p. 12; y núm. 12, 9 de diciembre de 1966, Boletín de diciembre de 1966, p. 17, en la que adujo no poder aplicar el artículo 105 por falta de ley de desarrollo. Sobre el mismo tema, la inamovilidad constitucional, pero en la jurisdicción contencioso administrativo, Sentencia núm. 9, 18 de abril de 1966, p. 9. No obstante lo antes expuesto, también se vertieron criterios a favor de la consideración de la ley fundamental como normas de derecho de aplicación directa, véase Sentencia núm. 7, 3 de junio de 1969, Sala de Garantías Constitucionales y Sociales, Boletín, IV, año 3, mayo-junio de 1969, pp. 186 y 187. Véase Prieto Valdés, Martha, "En pos de la aplicabilidad directa de la Constitución cubana de 1976 (un breve comentario)", Revista IUS, ICI-Instituto de Ciencias Jurídicas de Puebla, nueva época, año II, primavera de 2008, pp.193-204. 
1973 mediante ley ordinaria, aun cuando debió ser de carácter extraordinario o parte de la ley fundamental, la que reformuló el sistema de tribunales, diseñando una unidad orgánica con subordinación al poder revolucionario. ${ }^{25}$ Con tal ordenación, se suprimió la Sala de Garantías Constitucionales y Sociales, así como los procesos constitucionales, e incluso la existencia de una vía para las reclamaciones de parte respecto a disposiciones generales que pudieran restringir el alcance constitucional o los derechos en ella consagrados; no habría más cuestionamientos de constitucionalidad.

Así entonces, se daba paso a una reafirmación del poder, se sujetaba a los tribunales al nuevo gobierno que tenía facultades constituyentes, sin haberse modificado la norma superior, y todo ello sentó las pautas para la afectación de la noción de la normatividad e imperatividad de la Constitución y de su eficacia. El principio de supremacía constitucional dejaría de ser invocado, y en su lugar una nueva legalidad debía imponerse junto al fortalecimiento del gobierno y su administración pública que concentraba y centralizaba el poder a fin de hacer efectiva la toma de decisiones; consiguientemente, no se crearon espacios en los que se pudieran cuestionar la legalidad y la constitucionalidad.

\section{EL HOY, ¿EFECTIVIDAD?}

El último periodo comentado fue el presupuesto inmediato y más claro del diseño actual de control de constitucionalidad de las disposiciones generales o en caso de reclamaciones concretas. El rechazo a la actuación de aquel Tribunal de Garantías en 1952 y los conceptos contenidos en la antes mencionada Ley de $1973,{ }^{26}$ pasaron a la Constitución de 1976, en la que no sólo está ausente la jurisdicción constitucional sino que tampoco hay vía ordinaria ni proceso para sustanciar cuestiones de constitucionalidad

25 Véase Ley núm. 1250, 23 de junio de 1973, artículos 1o., 3o. y 5o. La Ley de referencia estableció un sistema único, integrado por los tribunales populares de base, regionales, provinciales y el Tribunal Supremo; y todo el sistema dirigido por el Consejo de Gobierno. Asimismo, determinó la subordinación jerárquica de los tribunales al Consejo de Ministros.

26 La Ley núm. 1250, 23 de junio de 1973, artículos 19, 32, inc. a) y del 97-103. La precitada Ley no sólo suprimió la Sala de Garantías Constitucionales y Sociales, sino que incluso estableció la competencia del Consejo de Gobierno del Tribunal Supremo para evaluar las consultas de los tribunales inferiores ante los posibles conflictos normativos, e hizo desaparecer la inamovilidad judicial. 
en situaciones particulares en caso de lesiones a los derechos básicos. No puede desconocerse la influencia de los entonces Estados socialistas, y el modelo soviético, ${ }^{27}$ con la noción de la supremacía del representante popular, y de su ejercicio de la soberanía a nombre del pueblo y de la unidad de poder, en que el aparato de justicia venía entonces a convertirse en un simple aplicador de la Ley, pero no su controlador. En este cambio de modelo tampoco puede obviarse el interés por asegurar la instrumentación inmediata de las decisiones adoptadas por el gobierno, la reafirmación de las medidas transformadoras y limitar su cuestionamiento.

Y si bien es cierto que en los primeros años posteriores a 1976 aún era una práctica de los jueces, en especial de las salas del Tribunal Supremo Popular, fundamentar sus decisiones con la Constitución para hacer sus valoraciones, empezaron a hacerlo como norma de acompañamiento y no decisoria. ${ }^{28}$ En consecuencia, vale reafirmar que ya en este periodo la noción acerca de la Constitución, aunque se admite que es norma, deja de ser en la práctica política y judicial regla de aplicación directa, y fue asumida más como reflejo de las conquistas alcanzadas que como límite al poder. ${ }^{29}$ Así, todo devino en el actual control político limitado.

27 Con esa lógica, a los efectos de la impartición justicia desaparecieron los órganos unipersonales y se constituyeron los tribunales de manera colegiada a todos los niveles, integrados tanto por jueces profesionales como por legos, revocables. Asimismo, extrajo el control de legalidad de los tribunales y lo asignó a la Fiscalía, que también se subordinó al Consejo de Ministros. Véase Ley núm. 1250, artículos 3o., 92, 129-168. Sobre el modelo soviético y su impacto en Cuba desde los primeros años (aunque también se observan en el diseño actual, nota de la autora de este trabajo), véase Merino Brito, Eloy (Magistrado del Tribunal Supremo), "Sistemas judiciales en los países capitalistas y socialistas", mayo de 1962; y Hart Ramírez, Enrique (presidente del Tribunal Supremo), "Discurso de apertura del año judicial, 3 de septiembre de 1962”, en Rodríguez Fernández, Yumil, Los tribunales en Cuba. Pasado y actualidad, La Habana, Oficina del Historiador de la Ciudad-ONBC, 2013, pp. 321-323 y 344, respectivamente.

28 La consideración de la Constitución como normatividad empezó a decaer a partir de 1979 y 1980, como pauta interpretativa de otras disposiciones o norma de aplicación directa, lo cual se puede constatar de la revisión de las sentencias publicadas en los boletines del Tribunal Supremo Popular. Para ampliar en este análisis véase Prieto, Martha, "El derecho, la Constitución y su interpretación", en Pérez Gallardo (coord.), Perspectiva del derecho cubano actual, Madrid, Reus, 2006, pp. 31-97.

29 Castro, Raúl, "Discurso pronunciado en el Acto de Proclamación de la Constitución socialista de 1976", Revista Cubana de Derecho, La Habana, núm. V, 1976, "La Constitución que hoy ponemos en vigor... consolida jurídicamente lo ya logrado... y norma, en correspondencia con las nuevas relaciones... los objetivos plateados en la cons- 
El control político de las leyes se previó tanto preventivo como posterior. En cuanto al primero ${ }^{30}$ se fija en las propias manos de la Asamblea Nacional del Poder Popular, con atención en la Comisión de Asuntos Constitucionales y Jurídicos del órgano legislativo, la que debe, según la restringida regulación, emitir un dictamen de su concordancia con la Constitución y la técnica legislativa. Al estipularse este control previo, si no hay dictamen contrario, o si la propia Asamblea no lo aprecia, las leyes ya nacen con el voto de constitucionalidad a su favor, con lo que deja de tener sentido el control posterior sobre las leyes. Esta actuación no ha sido transparente, como tampoco se ha dado publicidad de los debates en el órgano legislativo sobre la constitucionalidad de un proyecto si lo hubiera, lo cual debe ser tenido en cuenta en el proceso de perfeccionamiento del aparato estatal en pos de su mejor funcionalidad y lógica en la concepción integral. Igualmente, a tales efectos sería conveniente que el proceso de elaboración de las leyes goce de publicidad en todo momento, tanto respecto a los proyectos como a los debates vinculados a su elaboración; lo que permitirá conocer los fundamentos de estas disposiciones generales, y se tendrá de manera inmediata claridad sobre su legitimidad formal.

El control que más dudas ofrece en cuanto a su posibilidad de realización, es el político concentrado y posterior de las leyes en manos de la propia Asamblea Nacional del Poder Popular que aprueba estas mismas disposiciones, ${ }^{31}$ en tanto en ella se funden controlador y controlado. ¿Para qué hará falta otro control político concentrado en manos de la propia Asamblea que aprobó la ley, cómo sería posible su instrumentación, si ya las leyes han sido objeto de control previo al nacimiento y nacieron con el voto favorable de constitucionalidad? ¿Podrá la misma Asamblea que crea

trucción del socialismo...”, pp. 123 y 127; “El contenido de estos artículos no limita sino que asegura las libertades de las mayorías...".

30 Véase Reglamento de la Asamblea Nacional del Poder Popular, 1996, Sección Control constitucional del proyecto de ley, artículo 69. El dictamen desde el punto de vista de su concordancia con la Constitución y la técnica legislativa es facultad de la Comisión que atiende los asuntos constitucionales y jurídicos, la cual podrá realizarlo simultáneamente con el dictamen que realiza la Comisión especializada en un plazo no mayor de 30 días hábiles; y 70. Una vez cumplido lo que se señala en el artículo anterior, el dictamen se envía al presidente de la Asamblea Nacional.

31 Véase Constitución de la República de 24 de febrero de 1976, ref. en 1978, 1992 y 2002. Véase artículo 75. Son atribuciones de la Asamblea Nacional del Poder Popular: c) decidir acerca de la constitucionalidad de las leyes, decretos-leyes, decretos y demás disposiciones generales. 
las leyes declarar la inconstitucionalidad de su propio producto jurídico? Un sinsentido que merece ser profundamente cuestionado pues en todo caso aparece la Asamblea Nacional como juez y parte de tal proceder, lo que significaría ir contra sus propios actos, salvo que se refiera a leyes de la provisionalidad revolucionaria, o del tiempo de la neocolonia; pero lo cierto es que ninguna ley se hace mirando sólo al pasado.

También se ha concebido un control concentrado político-abstracto, para otras disposiciones generales luego de su entrada en vigor, como es el caso respecto a los decretos leyes y decretos, con lo que la Asamblea sí podría jugar su rol de órgano superior de control; pero a ello le sumamos que aún, luego de casi 40 años, no tiene tampoco instrumentación legal ordinaria. Su no realización afecta la normatividad y obligatoriedad de los mandatos constitucionales al desconocerse lo que se establece en el artículo $75 \mathrm{ch}$ ). Téngase en cuenta que el Consejo de Estado - en su carácter de órgano permanente de la Asamblea Nacional - aprueba decretos-leyes, ${ }^{32}$ derogables también por el Legislativo. Merece introducirse aquí otro comentario que separa práctica y normatividad constitucional, y es el hecho de que por decisión de la propia Asamblea los decretos leyes, no sólo tienen fuerza de ley, sino que también pueden modificar la ley; algo que merece revisión, a fin de que en lo cotidiano puedan efectivamente ser revocados, si fuere necesario por ella misma.

En cuanto a este último control concentrado y posterior, que es el que operativamente más se necesita a fin de asegurar el adecuado desarrollo de la letra mayor y la instrumentación de las leyes conforme a los límites definidos, es prudente destacar la involución que se ha producido en su construcción reglamentaria, con implicaciones negativas hacia su imple-

32 Véase Constitución de la República, ref., artículo $75 \mathrm{ch}$ ) es facultad de la ANPP revocar en todo o en parte los decretos-leyes del Consejo de Estado. Vale destacar la importancia de la facultad revocatoria de la Asamblea por el contenido del artículo constitucional $90 \mathrm{ch}$ ), al amparo del cual es el Consejo de Estado el órgano facultado para otorgar una interpretación obligatoria a las leyes, por lo que sólo resta a favor de la Asamblea la interpretación de la Constitución mediante las leyes que ella dicta. Igualmente, el Reglamento de la Asamblea Nacional del Poder Popular de 1996, vigente, establece en el artículo 83. La Asamblea Nacional puede revocar los decretos o disposiciones del Consejo de Ministros que contradigan la Constitución o las leyes. Asimismo puede revocar o modificar los acuerdos o disposiciones de los órganos locales del Poder Popular que violen la Constitución, las leyes, los decretos-leyes, decretos y demás disposiciones dictadas por un órgano de superior jerarquía a los mismos; o los que afecten los intereses de otras localidades o generales del país. 
mentación. Es así, ya que el primer reglamento de la Asamblea Nacional del Poder Popular, dado en 1977, fijaba pautas claras para su realización, ${ }^{33}$ se reiteraron tales preceptos, pero como parte de una disposición transitoria única en el Reglamento de 1982, mientras que en el vigente se consigna como derecho de los diputados la solicitud ${ }^{34}$ y se concentra en el control previo ya antes comentado.

De la propia previsión constitucional vale destacar otro tipo de control de la constitucionalidad, de carácter político-abstracto, posterior, no concentrado, que se desprende del funcionamiento de los órganos de poder. Ello resulta de la propia regulación del magno texto, definiendo que los órganos representativos, como es el caso del Consejo de Estado y las asambleas municipales del Poder Popular puedan intervenir. Cierto que tampoco tiene instrumentación legal, pero la regulación constitucional es clara: el órgano superior puede derogar, suspender o revocar disposiciones de los órganos inferiores que transgredan la Constitución, ${ }^{35}$ por lo que no

33 Véase Reglamento de la ANPP, 18 de julio de 1977, capítulo ocho. Del modo de decidir acerca de las cuestiones de constitucionalidad de las leyes, Decretos leyes, Decretos y demás disposiciones generales, artículos 93-98, en los que se determinaba quiénes podían plantear las cuestiones de constitucionalidad, entre los que merece destacar a las 25 personas que se hallaren en el pleno goce de sus derechos civiles y políticos; que la cuestión podía ser de forma o de fondo, el procedimiento interno en la Asamblea y la notificación al promovente de la decisión, bien fuera éste un diputado, un organismo o los ciudadanos.

34 Véase Reglamento de la ANPP, 1996, artículo 16 inc. e).

35 Véase Constitución de la República, ref., para el Consejo de Estado, artículo 90, ñ) y o): son atribuciones del Consejo de Estado: ñ) suspender las disposiciones del Consejo de Ministros y los acuerdos y disposiciones de las asambleas locales del Poder Popular que no se ajusten a la Constitución o a las leyes, o cuando afecten los intereses de otras localidades o los generales del país, dando cuenta a la Asamblea Nacional del Poder Popular en la primera sesión que celebre después de acordada dicha suspensión; o) revocar los acuerdos y disposiciones de las administraciones locales del Poder Popular que contravengan la Constitución, las leyes, los decretos-leyes, los decretos y demás disposiciones dictadas por un órgano de superior jerarquía, o cuando afecten los intereses de otras localidades o los generales del país... para las asambleas municipales del Poder Popular, artículo 106, d): revocar o modificar los acuerdos y disposiciones de los órganos o autoridades subordinadas a ella, que infrinjan la Constitución, las leyes, los decretos-leyes, los decretos, resoluciones y otras disposiciones dictados por los órganos superiores del Estado o que afecten los intereses de la comunidad, de otros territorios, o los generales del país, o proponer su revocación al Consejo de Ministros, cuando hayan sido adoptados en función de facultades delegadas por los organismos de la Administración Central del Estado... 
ha de necesitarse ley de desarrollo para que se instrumente en la práctica. La falta de publicidad respecto a estas decisiones, si se hubieren adoptado, no permite valorarlas.

Desde la lógica del control plural antes enunciada, atípica intervención es la que se ha previsto recientemente para el titular del gobierno en el Decreto Ley 272 del 2010, ${ }^{36}$ que expresamente establece la facultad del presidente del Consejo de Ministros, de velar por el respeto de la Constitución, aunque no es expresamente control de constitucionalidad, pero sí debe incidir en la salvaguarda de los postulados superiores: como sucede también respecto a la Fiscalía General de la República. ${ }^{37}$

Dentro de la dinámica nacional, los órganos abordados con anterioridad también realizan control de legalidad respecto a la gestión de los actos de gobierno y la administración pública, por lo que en la práctica este control debería asegurar la coherencia interna del ordenamiento, que ya nace sobre la unidad política. No obstante, las disfuncionalidades perviven al ser entendido el derecho - en lo cotidiano - sin distinguir entre jerarquías orgánicas ni normativas, y la legalidad como sujeción a la voluntad normativa del Estado.

Al asimilarse el control de legalidad como el genérico, obviarse el relativo al aseguramiento de la supremacía constitucional como el primero a realizar, y extraerse ambos objetivos de la sede judicial, y no estimularse las valoraciones acerca de las antinomias que se presentasen en el ordenamiento jurídico en sede judicial, se inaprecia el valor del control para asegurar coherencia y unidad en el ordenamiento jurídico.

Un último detalle sobre el control posterior y que evidencia una contradicción. Si bien el texto constitucional no prevé la intervención directa de los tribunales populares en el control de constitucionalidad de las leyes de manera directa, ni como resultado de procedimientos de defensa de derechos ciudadanos de ese rango, ello no le resta obligación a estos órganos

36 Decreto Ley 272 de 2010, artículo 20, inc. b). Son facultades del presidente del Consejo de Ministros: cumplir y velar por el respeto de la Constitución de la República, las leyes y demás disposiciones del Estado.

37 Constitución de la República de Cuba, ref., artículo 127. La Fiscalía General de la República es el órgano del Estado al que corresponde, como objetivos fundamentales, el control y la preservación de la legalidad, sobre la base de la vigilancia del estricto cumplimiento de la Constitución, las leyes y demás disposiciones legales, por los organismos del Estado, entidades económicas y sociales y por los ciudadanos... 
de cumplir la Constitución ${ }^{38}$ en su función de impartir justicia y defender los derechos. Entonces nada impide su participación en un control para caso concreto ante violación o lesión de derechos consagrados en la suprema ley. ¿No deben los tribunales resolver las antinomias que se presenten en la solución de los casos que conocen? ¿Y si detectan infracciones de la constitucionalidad no deben resolver la contradicción normativa, no deben salvar la omisión que lesiona derechos? No hacerlo supone un límite a la eficacia constitucional, y es lo que se produce.

En otras palabras, hay una concepción amplia del control, que prevé una diversidad de órganos intervinientes en el de constitucionalidad, fusionado con el de legalidad, lo que a juicio de esta autora, además de los factores de índole política, ha limitado la garantía de superioridad y no ha fluido con la eficacia requerida.

Entre las causas de la limitación anterior pudiera señalarse que, en la esfera práctica política de los últimos años ha habido un malentendido respecto a lo que es el control, que no es exceso de limitación o imposición de restricciones; sino que es vigilancia y exigencia del cumplimiento de lo establecido. En síntesis, la noción de límite ha sido el primer problema en torno al control del poder y su actuación; i¿cómo limitarlo?!; el segundo la falta de interés acerca de ese necesario control plural, y el tercero, la ausencia de previsión legal de qué hacer y cómo hacer, sin descontar la indefinición de los medios de exigir responsabilidad a los órganos mandatados para desarrollar la preceptiva constitucional o mandatados para darle cuerpo legal a las reglas superiores, cuando no lo han hecho. Tales ausencias o desregulaciones limitan la instrumentación de valores y principios constitucionales que conducen a una inconstitucionalidad por omisión y el camino hacia la desconstitucionalización del ordenamiento jurídico cubano, con sus efectos nocivos para el diseño sociopolítico y para los derechos humanos en el texto contenidos.

La anterior situación entra en directa contradicción con principios y postulados rectores que están en la base de nuestro ordenamiento jurídico-

38 El artículo 66 constitucional establece que el cumplimiento estricto de la Constitución y de las leyes es deber inexcusable para todos (las cursivas son de la autora del artículo para destacar el sujeto indeterminado y genérico que se empleó para designar a los obligados, todos sin distinción). Igual obligación se establece mediante la Ley de los Tribunales Populares de 1977, la que en los artículos 1.2 y 5, fija la obligación para los tribunales de cumplir la Constitución y las demás disposiciones legales. 
político: si la Constitución ha sido adoptada por el pueblo en voto aprobatorio directo, no hay dudas del lugar que debe ocupar, y cuánto y cómo ha de irradiar sobre toda la sociedad, a la vez que pautar la solución de las múltiples antinomias que en la práctica se manifiestan, de conformidad a lo que el propio texto constitucional ha previsto. Es por ello que sobre el control actual en Cuba se han venido produciendo análisis y propuestas para su reformulación. ${ }^{39}$

\section{LO NECESARIO EN EL HOY Y EL FUTURO INMEDIATO PARA ASEGURAR LEGITIMIDAD Y JUSTICIA}

En el proceso de hondas transformaciones económicas que se desarrolla hoy en Cuba, ante la necesidad de instrumentación de la descentralización empresarial, tributaria y administrativa, para el avance del país, hace falta perfeccionar los medios de control plural en esta materia a fin de asegurar que en aras de ello no se produzca un fortalecimiento de la centralización en todos estos ámbitos, porque de esta manera ni el control de legalidad político, ni el de constitucionalidad diseñado podrá instrumentarse como se requiere.

El hecho es que las medidas económicas están impactando en las esferas sociales y políticas, y todas ellas retumbarán en los valores. No sólo se producirá una desviación en el orden social, sino que aquí habría causa de conflicto social.

Entonces, ha de instrumentarse el control en su diversidad - ya popular, jurídico o político, de órganos representativos, judiciales, fiscales y de control, pero cada uno en su función diferenciada para evitar la disolución de la actuación - . Es ésta una exigencia de primer orden, acompañada de otros requerimientos, como transparencia, decisiones políticas y administrativas, previas y precisas; así, la determinación jurídica de las facultades de los órganos de la administración y del Estado, en sentido general, van acompañadas de la publicidad jurídica en todo momento.

De tal suerte, frente a cualesquiera de las lesiones o amenazas posibles como resultados de medidas de reorganización empresarial, administrativa y

39 Además de las publicaciones antes referidas, véase Matilla Correa, Andry (comp.), Estudios cubanos sobre control de constitucionalidad (1901-2008), México, Porrúa, 2009. 
del aparato de poder, ha de asegurarse la instrumentación del control previo político de constitucionalidad, sin obviar el control posterior asentado en la Asamblea Nacional o en cualesquiera de los órganos que están llamados para la detección de las posibles vulneraciones. También han de instrumentarse las reglas jurídico-políticas necesarias para la solución a las contradicciones normativas, asegurando además de la validez formal y material de las nuevas disposiciones, los derechos ciudadanos fundamentales. Es esta una exigencia para la eficacia de lo dispuesto constitucionalmente, en tanto no se reforme mediante el voto popular directo el texto y se conciba un control de constitucionalidad diferente, con intervención del aparato de justicia, para que sea realmente plural y efectivo.

Asimismo, no debe seguirse obviando que aún hoy los tribunales pueden y deben intervenir en el control de constitucionalidad, para la defensa de los derechos fundamentales, sin ser una exigencia la existencia de proceso o sala especial para ello. Basta que los tribunales resuelvan las antinomias presentes, inaplicando las inferiores restrictivas y aplicando la superior garantista como centro de su fallo. ${ }^{40}$

De cara a la próxima reforma constitucional, es necesario introducir expresamente la intervención del aparato de justicia en el control de constitucionalidad de las leyes y demás disposiciones generales, preferiblemente con efecto erga omnes, mediante una acción pública, individual y colectiva. No se descuenta tampoco la posibilidad de intervención de la Sala Especial $\mathrm{y}$ todos los tribunales de justicia para la defensa de los derechos constitucionales, a través del recurso de inconstitucionalidad o el amparo, a través de los que de manera concreta se inapliquen las normativas inferiores restrictivas y, a la vez, lesivas de derechos constitucionalizados; decisiones que de ser reiteradas, deben surtir efectos generales.

No obstante, y hasta en tanto no se produzca la reforma constitucional, a fin de recabar la vigilancia constante y el aseguramiento de la inalterabilidad de los contenidos constitucionales, es prudente que se instrumenten las siguientes propuestas:

40 Véase Prieto Valdés, Martha, "La Constitución, los derechos y el control. De Cuba, propuestas", cit., pp. 137-153; id., "Las garantías constitucionales de los derechos fundamentales y la Constitución de 1976", en Matilla Correa (coord.), La Constitución cubana de 1976; 40 años de vigencia, cit., pp. 170-188. 
- Establecer una clara diferenciación en la práctica política jurídica entre lo constitucional y lo legal u ordinario, sustentado en la diferente jerarquía de los entes intervinientes en el proceso de creación jurídica, con impacto lógico en los efectos de las decisiones. Ello hará más factible la instrumentación del control posterior concentrado en la Asamblea Nacional del Poder Popular y el que ejercen los demás órganos como parte de la verificación del funcionamiento de los inferiores en los marcos legales previstos.

- Reconocer la acción pública a favor del ciudadano - individual y colectivamente - como parte principal y estimulador del control político de la constitucionalidad ante la Asamblea Nacional respecto a las leyes, decretos leyes y decretos, con efectos erga omnes, interpuesta al amparo de la conjunción de los artículos constitucionales $3,26,63$ y $66 . .^{41}$

- De igual manera, si las acciones en pos de la institucionalidad han de ser tarea de todos, la ciudadanía también debe poder promover —en sede política - la revocación de disposiciones restrictivas de derechos consagrados constitucionalmente, expresión también del control popular previsto entre los principios de organización y funcionamiento del Estado cubano. ${ }^{42}$

41 Constitución de la República de 1976, ref. 2002, artículo 3o., párrafo 2: Todos los ciudadanos tienen el derecho de combatir por todos los medios, incluyendo la lucha armada, cuando no fuera posible otro recurso, contra cualquiera que intente derribar el orden político, social y económico establecido por esta Constitución; 26: Toda persona que sufriere daño o perjuicio causado indebidamente por funcionarios o agentes del Estado con motivo del ejercicio de las funciones propias de sus cargos, tiene derecho a reclamar y obtener la correspondiente reparación o indemnización en la forma que establece la ley; 63: Todo ciudadano tiene derecho a dirigir quejas y peticiones a las autoridades y a recibir la atención o respuestas pertinentes y en plazo adecuado, conforme a la ley; y 66: El cumplimiento estricto de la Constitución y de las leyes es deber inexcusable de todos.

42 Véase Constitución de la República de 1976, ref. 2002, artículo 68, inc., b), las masas populares controlan la actividad de los órganos estatales, de los diputados, de los delegados y de los funcionarios. 
Para los dos casos anteriores, podría retomarse la iniciativa popular, ciudadana y colectiva - contenida en los anteriores reglamentos de la Asamblea Nacional, ya comentados- ${ }^{43}$

- Estimular igualmente, a favor del ciudadano - individual o colectivo - el acceso pleno a la justicia que, como medio para la defensa de los derechos fundamentales, estimule el control de la legalidad y de la constitucionalidad concreto en sede judicial, ya sea ante todos los tribunales o de manera concentrada en la Sala Especial hoy admisible, ${ }^{44}$ correspondiéndole a la Asamblea Nacional la declaración de nulidad o invalidez de la disposición, por inconstitucionalidad o ilegalidad, todo lo cual es de posible instrumentación sin necesidad de reforma constitucional.

Las dos propuestas anteriores descansan en la máxima de que si desconocer la acción ciudadana directa vacía de contenido la catalogación como democrático de cualquier diseño político, hoy se debe restablecer la acción de uno o varios ciudadanos para estimular el control, por cualquiera de las vías.

\section{IN FINE}

Sólo un control plural, en cuanto a los diferentes tipos de órganos que participan (políticos y judiciales), y con una diversidad de actores estimulándolo, todos exigiendo y verificando el cumplimiento de la Constitución, será posible la salvaguarda de su supremacía y de los contenidos esenciales que la informan, lo que es además una exigencia para hacer valer la voluntad del pueblo en su carácter soberano y constituyente $\mathrm{y}$, con todo ello, legitimidad de las disposiciones y la justicia.

43 Véase supra nota 32. Además de los 25 ciudadanos, podían promover acción por cuestiones de constitucionalidad de las leyes, decretos leyes, decretos y demás disposiciones generales a los diputados, al Consejo de Estado, al Consejo de Ministros, los Organismos de la Administración Central del Estado, la Fiscalía General de la República, el Tribunal Supremo Popular, las direcciones nacionales de las organizaciones sociales y de masas.

44 Ley de los Tribunales Populares, núm. 82 de 1997, artículo 24, inc., b) que conoce de las revisiones que se establecen contra sus propias sentencias decidiendo los recursos a que se refiere el inciso anterior. 
En otras palabras, en materia de control debe también debe tenerse en cuenta la máxima martiana de que la República se instituya con todos y para el bien de todos,${ }^{45}$ lo que sólo puede tener como finalidad alcanzar conjugadamente el bienestar individual y colectivo que encabeza la Constitución ${ }^{46}$ y asegurar el ejercicio de los derechos y opiniones de los hijos todos de los que está hecho un pueblo. ${ }^{47}$

45 Martí y Pérez, José. "Discurso con todos y para el bien de todos", Obras Completas, Ciencias Sociales, La Habana, Liceo Cubano de Tampa, 26 de noviembre de 1891, 1975, t. 4, p. 269.

46 Constitución de la República, ref., artículo 1o.: Cuba es un Estado socialista de trabajadores, independiente y soberano, organizado con todos y para el bien de todos, como república unitaria y democrática, para el disfrute de la libertad política, la justicia social, el bienestar individual y colectivo y la solidaridad humana.

47 Martí y Pérez, José. "Los pobres de la tierra", Obras completas, cit., t. 3, p. 304.

Fecha de recepción: 28 de junio de 2016.

Fecha de dictamen: 28 de abril de 2017. 